\title{
sciendo
}

\author{
MARTA KOTOMSKA ${ }^{1,2}$, ALDONA MICHALAK $^{1,2}$
}

\section{Communication and perioperative care of elderly patients}

\begin{abstract}
Communication is one of the basic human needs, it builds trust and facilitates people-to-people contacts. This is widely understood exchange of information as well as feelings, it is both; discussion and argumentation.

The basis for effective treatment is proper communication between the medical staff and the patient. Nurses, medical careers working with elderly people are often in a situation where it is difficult for them to communicate with the patient. Ignorance of the physiology of human aging, difficulties and diagnostic limitations may lead to errors of medical personnel.

The objective of the article is to draw attention to the role of communication among nurses, supported by medical caregivers, who deal with an elderly patient in pre-, peri- and postoperative period, as well as to point out that nursing staff is insufficiently involved in creating standards of medical care.

Lack of training, outlines and guidelines in the field of communication and geriatrics, in the treatment and care of elderly patients result in ignorance, intuitive, incomplete and accidental action, without intentional continuity, what may result in deterioration of care and may contribute to an increase in perioperative mortality of older people.
\end{abstract}

Keywords: communication, perioperative care, old age (elderly patient).

DOI: $10.2478 /$ pjph-2019-0013

\section{BACKGROUND}

The average life expectancy has definitely extended in Poland. It is estimated that in 2020 individuals aged more than 60 will account for $25 \%$ of Polish population. The forecast for 2008-2035 drawn up by the Polish Central Statistical Office (GUS) reveals that the number of individuals aged at least 85 may reach nearly 800,000 in 2030 [1].

Old age is a condition resulting from ageing, the last period of human life. It primarily encompasses biological (physiological), cognitive, emotional and social changes [2].

Nowadays, the age of 60-65 (namely retirement age) is considered to be the threshold of old age. This is an artificially defined boundary and refers rather to social grounds than to actual physiological age. Nevertheless, ageing is a fact and encompasses certain limitations in functioning of the human body. It is "a loss of physiologic reserve, combined with disorders of endocrine system and dysfunction of immune system" [2].

The concept of old age in the medical sense encompasses physiological changes in human body (organ "wear and tear", reduced cell regeneration) of the elderly. In this period cells cease to intensively proliferate, the body becomes more susceptible to diseases, and nervous system becomes less active. Human tissues become dehydrated and less flexible. They undergo atrophy [2].

Medical professionals encounter elderly patients in their everyday practice even more often. Such patients constitute a very heterogeneous group and frequently suffer from numer- ous concomitant diseases [3]. Communication with them is often difficult. The role of the nurse, who stays with the patient for the longest time and is the closest to their problems and suffering, cannot be underestimated. It seems that perioperative care may be improved if empathetic nurses, well-trained in communication and geriatrics, who play an important role in therapeutic team, are employed.

\section{INTRODUCTION}

Civilization-related changes and progress in medicine prolong human life expectancy. This results in an increase in the number of elderly in society. Therefore, it is necessary to prepare therapeutic teams, including nurses working at surgical wards and operating theatres, to care for elderly patients.

If a good care plan is to be created, it would require multidisciplinary, comprehensive, preoperative assessment in case of the elderly. All members of a therapeutic team should be involved in assessment of patient's condition. Multidisciplinary (internal medicine, geriatric, anaesthetic, surgical, psychological, rehabilitation, nursing and care) teams should be organised for this purpose.

Lack of guidelines, outlines and training in the field of treatment and care of elderly patients results in unawareness, intuitive incomplete accidental action without continuity, and thus deteriorated care. This may also contribute to increased perioperative mortality of the elderlies.

${ }^{1}$ Chair and Department of General and Transplantation Surgery, Transplantation Institute, Warszawa, Poland

${ }^{2}$ Department of Surgical and Transplantation Nursing, and Extracorporeal Treatment, Medical University of Warsaw, Poland 
Incidence of complications and fatality rate are even higher with the so-called acute (unplanned) surgeries that are associated with significantly higher risk than the planned ones, because patients undergoing acute surgery are more prone to perioperative complications and there may not be enough time to optimize their health status. That is why surgery should not be postponed only due to patient's old age [4].

Specialist surgical, anaesthetic and operative nursing prepares a nurse to carry out a care plan in the field of:

- preoperative care (diagnosis, surgery preparation);

- intraoperative care (when a patient stays at the operating theatre);

- postoperative care (recovery and re-gaining independence).

It also seems important to carry out training in broadly understood geriatrics at surgical wards.

Age over 80 years is considered a risk factor for serious complications (myocardial infarction, stroke) observed in perioperative period. It is the age that is listed as a factor, independent of comorbidities, increasing the risk of perioperative complications in all scales (literature lists 19 scales, 5 of which are most frequently used: Euro SCORE, STS, Parsonnet score, Cleveland clinic scoring tool, NNE score) [5].

Each patient, an elderly patient in particular, should be prepared for surgery, starting from the first outpatient visit. While taking a detailed history, a physician gets to know test results, asks about addictions, co-morbidities, assesses nutrition and hydration status, and sets up a treatment plan [6]. The main goal of medical care should be to enable proper communication with the elderly patient and provide emotional support. It is important to obtain information about the degree of hearing or visual impairment and preferred communication methods during the history-taking process. These information should be placed in patient's chart, made available to the entire therapeutic team at the surgery wards.

The so-called geriatric nursing assistants should become members of such team. Health care assistants may play this role. These are individuals who provide professional assistance to a sick and dependent person to satisfy their basic life needs. A health care assistant identifies and solves care-related issues of dependent individuals at different ages with disease at various stages. It is a person who helps an individual under their care to satisfy their biopsychosocial needs. While assisting the medical staff (nurses, physiotherapists) in taking care of a patient, an assistant helps them, supporting sick and dependent person at the same time. A health care assistant provides medical care over the patient and undertakes cooperation with a therapeutic team [7].

Qualifications in the profession of health care assistant may be officially acquired in Poland since 2008. Education takes place at vocational and post-secondary vocational schools. In the course of six years approx. 20 thousand individuals were educated, half of them passed the state examination, but merely one in four of them was employed. Nurses assess preparation of health care assistants in a positive manner. Thanks to them they can count on assistance of well-trained support staff [7].

\section{Preoperative care}

Despite development of medicine, a surgical procedure causes injury to human body and is associated with the risk of postoperative complications. This risk increases with patient's age and is in direct proportion to concomitant diseases. The elderly often have cognitive function deteriorated, are more susceptible to stress factors, and suffer from sleep disorders, disorientation, apathy or agitation. Decreased physical activity, resulting from reduced muscle mass, deteriorates tolerance to exercise and leads to motor retardation [4]. Atherosclerotic lesions lead to increased blood pressure and degenerative lesions cause myocardial disease of various severity. Lung capacity is also reduced, while glomerular and hepatic blood flow decreases even by up to $40 \%$. Atherosclerosis also causes chronic intestinal ischaemia, disturbed fluid absorption and impaired nutritional status. Reduced number of lymphocytes and antibodies lead to greater susceptibility to infection [8].

Nowadays no patient can be refused surgery based on their age, but the risk of complications and perioperative mortality increase with physiological age and concomitant chronic disorders.

Surgery outcomes in elderly patients may be improved if they are referred earlier for surgery before complications may be an indication for emergency surgery, during which there is no time to optimize patient's status, diagnose concomitant diseases and prepare them for surgery. Round-the-clock nursing perioperative care, accurate monitoring and quick reactions to any abnormalities seem to be factors with impact on treatment outcomes that are perhaps even the most important.

Holistic nursing based on nursing theories that is thoughtout and purposeful serves to introduce the nursing process, being an organised process with preparatory, implementation and assessment stages (diagnosing, planning, executing and assessing) [9]. A nurse is a person who may and should devote time to a patient, while a trained one with knowledge and skills may theoretically and practically prepare a patient for surgery. However, a nurse has to demonstrate knowledge in general and clinical nursing. Specialist targeted vocational training obliges a nurse to implement a surgical care plan. Such plan involves mental and physical preparation.

Health care assistants trained in identifying and solving care-related issue of a sick and dependent person, providing assistance to such person as well as cooperating with care and therapeutic team, assisting a nurse in nursing procedures, would become a great help for nurses if they are employed at wards.

Mental preparation of a patient at surgical ward carried out by a nurse:

1. admitting a patient and helping with adaptation to hospital environment;

- getting to know a patient (introducing oneself);

- informing a patient about procedure date and time;

- assessing patient's knowledge and experience in surgery;

- assessing patient's cognitive abilities.

A nurse admitting a patient to the ward should pay attention to patient's awareness and cognitive abilities (whether a patient sees, hears and understands) to assess whether the patient can and should make all decisions independently and does not need constant care. Cooperation with the patient's family seems to be very important in this case provided that it is possible to determine the level of joint decision-making. A nurse must find out whether a patient understands benefits and risks of surgical treatment and independently assess patient's cognitive abilities to the best of their knowledge. In case of doubts a nurse should ask clinical psychologist for help and assessment of patient's awareness and self-determination capacity.

- assessment of patient's orientation in the place and time. 
An elderly patient who found himself/herself in a new place can have serious problems moving around the ward, locating areas he or she may use or find help in. The role of a nurse and health care assistant is to familiarise patients with a ward, find out whether they will be able to find their room, nurse station or toilet.

- discussing the need to prepare a patient before a procedure;

- discussing patient's management after surgery;

- clarifying any doubts;

- reducing stress.

Physical preparation of a patient admitted to a surgical ward The risk of postoperative complications may be reduced if a patient is properly prepared. The role of a therapeutic team includes but is not limited to:

1. Assessing patient's motor skills;

Elderly patients often have problems with moving on their own. Due to concomitant musculoskeletal diseases, such patients have to use walking sticks or walking frames. A physiotherapist who will teach a patient to use devices that help them move independently is indispensable in such case.

2. Learning to perform breathing exercises;

Surgical procedure and associated surgical wound pain reduce the capacity of deep breathing and expectorating. This may lead to lung inflammation and respiratory failure. In order to avoid such problems, time before the procedure should be used for breathing rehabilitation exercises involving i.a. active expectoration and coughing.

3. Assessing nutritional status;

Malnutrition is caused by loss of appetite, decreased physical activity and concomitant diseases. Malnutrition undiagnosed and untreated in the perioperative period increases the incidence of complications. It seems logical to pay attention to this issue before the procedure, during early referral or upon admission, as it may have favourable effect on treatment outcome [10].

\section{Assessing hydration status;}

Severe disease in elderly patients is associated with thirst and appetite disorders. Patient's hydration status is assessed during history-taking, i.e. conversation with a patient and his/ her family, and physical examination. The purpose of historytaking is to find out about the quantity of fluids ingested and excreted by a patient. Mucosal hydration, ocular pressure, skin hydration, peripheral oedema and pulse rate are assessed during physical examination. Preoperative fluid therapy has a beneficial effect on maintaining or restoring normal circulation as well as water and electrolyte balance, what contributes to better treatment outcome.

\section{Close observation of behavioural changes}

Observation and rapid response to behavioural changes of an elderly patient will be possible only if a nurse is very engaged, well-trained, empathetic and has knowledge in various fields of nursing and related sciences (psychology, rehabilitation). Cooperation between nurses working on different shifts, passing on significant information and suggestions about patient care guarantee good care and preparation of the patient for surgery.

It should be noted that verbal and non-verbal communication does not always express the same. Non-verbal communication is often more important in patient care. It may tell us more about patient's emotions and mood than verbal, generally conventional, message. Non-verbal communication is of particular importance while caring for a demented patients or patients with delusions, cognitive disorders, who usually express one thing in words while their bodies say something else.

Haptic communication is a very desired communication type.

Caregivers, staff in hospices, long-term care facilities are being trained in proper touch throughout the world, because the suffering ones consider such touch to be the longest talk possible. Touch is an important source of information about our attitude to a patient, bed-ridden ones in particular. Even the most polite statement will not replace it. It is a pity that this form of communication remains underestimated in Polish health care system and, what is even worse, is often perceived by outsiders as familiarizing with patients or taking away their sense of dignity.

The right attitude towards a patient is the most significant part of management that has impact on both the outcome and the entire treatment [11].

\section{Care at the operating theatre}

Patient at the operating theatre is often treated as a "case" (gall bladder, hernia, fistula), or a diagnosis placed on the operating table. We often forget that this human being may be scared, insecure, lost or may have problems with hearing, eyesight or moving on their own. Elderly patients are very diversified in terms of physical and mental fitness.

Care at the operating theatre is based on psychological impact, aimed at reducing stress and creating a friendly atmosphere that allows a patient to forget about the surgery and overcome any inconvenience related to preparation (insertion of intravenous cannula, putting on the mask to saturate the patient with oxygen, watching preparations for the surgery at the operating theatre).

A patient is brought to the operating room by a nurse who is obliged to provide all relevant information about the patient. It is important to inform the staff about possible hearing, eyesight problems, or whether the patients is calm, scared, understands what is being said to him and whether he can logically communicate and respond to commands. It should be noted that patient's awareness is altered not only by action of drugs but also by stress. Such individual ends up in foreign environment, sees people dressed in the same way and stops being a full member of the therapeutic team aware of their rights, instead becoming a "subject of certain actions carried out by the staff'.

Aware operating staff has to remember that patient management may differ. An elderly patient (or any patient) may have problems with eyesight, hearing or accepting the circumstances.

That is why it is important that a nurse bringing a patient provides information about any physical or mental limitations. They should be provided to the operating theatre in advance and a nurse or nurses, either operating room nurse or nurse anaesthetist, meet patients one day before and their limitations do not seem to matter. The most important thing is that the patient brought to the operating theatre does not feel strange and lost.

It is not necessary to deprive the patient of a hearing aid (in case of severe hearing loss) or glasses (if poor eyesight significantly impairs motor capacity). The same applies to a dental 
prosthesis, if it is not necessary, the patient can remove it just before anaesthesia. Nurses can agree upon who is responsible for these things when bringing the patient. Hearing aid and glasses may be taken off after the patient is sedated when they are no longer needed.

The sense of security, mental and physical comfort of the patient are more important rather than trying to get rid of the issue with securing and watching for devices that help the patient communicate. Hearing aid may be put in its place before awakening to make communication easier.

Frequently an anaesthetist shouts at a hearing-impaired patient, turns away and automatically starts shouting at a nurse. Such situations cause discomfort for the patient, and frustration and chaos in the therapeutic team.

Some elderly do not want to admit to hearing deterioration and they have to guess what is going on. Communication is distorted.

Communication requires more and more effort as hearing loss progresses. An elderly patient with poor hearing is watching the interlocutor very carefully, observing every gesture, keeping track of every mouth movement, using lip-read to fill in missing information.

A person talking with a hearing-impaired person should take off a procedure mask. Conversation with a patient should not be started if it is too loud or too much going on in the room. It should be conducted face to face, clearly and in slower pace than usual, with good lighting. If a patient hears better on one ear, it is better to speak to this ear. If an elderly with hearing impairment uses only one hearing aid, a person talking should stand on the side of the device. It is important to listen carefully to what the patient says without doing anything else. One has to be prepared that speech may be distorted, so it is important to listen carefully. More attention should be paid to understanding what the patient wants to convey to us, showing no impatience, without rushing and interrupting the patient. Noise and loud conversations near the patient should be avoided, if possible. If the patient does not hear at all, communication must take place in writing [12].

Patient with hearing or sight impairment also feels lost. Other senses of visually impaired people get enhanced, e.g. touch and hearing; that is why speech, followed by touch, is the basic way to communicate with an elderly person. One should talk to such patients, gently touching them, clearly pronouncing their name, so that they know that we are talking to them. A nurse should inform the patient about what is going on. The next steps should be announced during procedures. This will help avoid surprise, sudden and uncontrolled reflexes, and a patient will be comfortable and have control over the situation. Furthermore, patients should be informed if a nurse has to leave them.

It should be noted that visually impaired individuals have other senses, unless they are impaired. Sometimes medical staff forgets about it. Visually impaired patients hear normally and understand everything said to them. While listening to a blind person, one should actively confirm, cutting in from time to time, saying e.g. "yes", "I understand".

Cognitive impairment is another issue. The following cognitive dysfunctions are distinguished: speech disorders (aphasia), cognition disorders (agnosia), motor disorders (apraxia), memory deficit (amnesia), orientation, thinking and remembering disorders. Impaired orientation triggers anxiety and readiness for various defence reactions, e.g. a tendency to behave in a persistent and stubborn way. Speech disorders impede contact with other people and affect self-esteem of a patient affected by this type of disability. Slurred speech, referred to as dysarthria, is an articulation disorder that involves incorrect pronunciation of certain sounds or incorrect speech rhythm. A patient understands what is being said, is able to formulate words and sounds, but has difficulty articulating them.

While talking to a patient with dysarthria, one should show patient, understanding and compassion. A patient with speech disorder should always be treated with attention and serious attitude, as well as with respect for dignity of a valued individual with specific skills, rights and obligations.

An important element is to obtain feedback from the patient to ensure that the information provided has been correctly understood. In case of patients with aphasia, techniques that increase the understanding of speech are most commonly used and the communication itself is based on illustrating verbal communication [13].

Patient is admitted to the operating theatre by nurse anaesthetist together with anaesthetist. In that room surgical nurses await, along with a surgeon and auxiliary staff.

It is extremely important to prevent physical complications (hypothermia, muscle and nerve compression due to incorrect position, patient's skin becoming dry on the sides after cleaning and placing surgical sheet to prevent burns during diathermy).

When a patient moves to the operating table, it is necessary to pay attention to their motor status. If necessary, someone should help patient move.

Accessories to the operating table (supports, cushions, straps) have to be prepared and tailored to procedure type as well as to physical disorders of the patients, condition of the musculoskeletal system or possible body deformations. Lying in a forced position for a long time may aggravate patient's physical disorders. Elderly patients are at higher risk of peripheral nerve injuries (radial and sagittal nerve, brachial plexus). Patient's position on the operating table should be as natural as possible, with supports in flexing areas, and should be checked during the procedure.

Pressure relief mattress should be placed while laying patient on the table. Attention should be paid so that the mattress does not roll up or get wet. Elderly patients are very prone to pressure sores which may become a complication, or cause pain and infection.

During electrocoagulation condition and hydration of the patient's skin must be observed to use appropriate passive electrode. Care should be taken when removing a disposable electrode so as not to damage patient's delicate skin.

Elderly patients are at greater risk of hypothermia compared to young patients, so it is important to maintain and control normal body temperature. Mattresses and heating blankets, warm infusion fluids prepared in advance will turn out to be helpful, and assessment will be made using surgical thermometers.

Shortening surgery time to a minimum may be seen as preventive measure reducing the number of postoperative complications. If the surgery time is extended by 30 minutes in a group of patients aged 65-79, the risk of wound infection, cardiac disorders, respiratory disorders and other complications increases by $15 \%, 17 \%, 7 \%$ and $18 \%$, respectively [5]. Apart from surgeon skills, there are numerous factors that have impact on surgery time. If a surgeon is able to work fast and 
efficiently, a patient has to be well anaesthetized, and surgical and auxiliary teams have to be prepared for every possible contingency.

It is unacceptable to use a condescending tone, e.g. "And now sweetheart just hop to the bed". Diminutives (granny, grandpa), treating the elderly like a child often irritate the patient. Communication must be clear and understandable, but expressed in an uncondescending manner.

Nurses working at the operating theatre are required to actively listen, concentrate, empathize and support the elderly patient. Surgical nurses are responsible for patients' comfort and safety from entering the operating theatre to being brought back to the ward. Nurses care for patients, listen to them, answer questions and dispel any doubts in line with their competences. Patients' well-being and making them feel welcome and cared for are the most important [11].

Surgical nurses are obliged to know the problems of vulnerable patients, and such group of patients includes the elderly. They should have high competences, knowledge in the field of psychotherapy in order to behave professionally as expected by patients.

Nursing care at the operating theatre is a prelude for further postoperative care preventing postoperative complications.

\section{Postoperative care}

The most difficult period begins when a patient awakes and leaves the operating theatre. Properly organized care significantly improves comfort, shortens patient's stay in the hospital and reduces the number of postoperative complications.

Early ambulation, verticalization, respiratory rehabilitation, prevention of pressure sores and feeding a patient soon after procedures at surgical wards speed up patient's recovery.

1. Early ambulation;

Early rehabilitation will help the patient to regain fitness from before the surgery and avoid numerous respiratory and circulatory complications.

2. Early diagnosis of possible complications:

- respiratory complications;

Early and active respiratory therapy may reduce the incidence of lung complications. Monitoring the patient with pulse oximeter seems sufficient. However, only a vigilant nurse will notice why a patient breathes in a too shallow manner. Respiratory exercises shown to a patient before the surgery may be useful [10].

- circulatory complications;

Myocardial infarction takes place not only in patients with a history of infarction. Uncontrolled pain, fear, hypoxia and hypothermia play an important role in the aetiology of myocardial infarction in the perioperative period. That is why it is necessary to observe the patient and monitor ECG. Normal oxygenation and temperature after surgery are of fundamental importance [10].

- acute confusional state and cognitive disorders;

This is a common complication after surgery under general anaesthesia in elderly patients that is difficult to assess. Its risk factors include dementia, concomitant diseases, atherosclerosis in particular, and the so-called drug-induced delirium [12].

Acute confusional state is noted in $15-53 \%$ of patients aged over 65 at surgical wards [14]. It seems to determine subsequent fate of the patient, their family and therapeutic team. Individuals who suffered from acute confusional state must reckon with long-term cognitive dysfunction, decreased daily life activity, and resulting reduced quality of life [15].

3. Monitoring and interpretation of the results.

4. Pain management.

5. Fluid therapy.

In the postoperative period, a quick return to the physiological route of fluid delivery should be considered, even several hours after the procedure. Parenteral hydration should be used only if oral route is contraindicated. Early enteral nutrition in postoperative period, also within the gastrointestinal tract, is important for earlier recovery and regaining independence.

6. Early return to nutrition from before surgery.

7. Assessing the patient's ability to self-care.

8. Establishing a self-care plan.

Postoperative treatment standards are difficult to define. Human factors, such as ratio of the number of nurses to the number of patients treated, coincide with factors allowing for early detection of complications related to a number of specialists, including nurses at the surgical ward [6].

Elderly patients share may features typical of this age group, which at the same time distinguish them from young individuals. These include:

- physiological differences;

- pharmacological differences;

- central nervous system disorders;

- postoperative loss of cognitive functions;

- low tolerance of complications.

A developed and introduced perioperative management protocol for elderly patients should include guidelines and recommendations regarding preparation for surgery, intra- and postoperative management. It has often been proven in medicine that the degree of protocol implementation correlates with treatment outcomes. Their introduction and application result in shorter patient's stay at the hospital and lower number of overall number of complications. ERAS (Enhanced Recovery After Surgery) - comprehensive perioperative care protocol to improve treatment outcomes - is a good example. Therapeutic teams have been trying for many years to improve surgery outcomes by reducing the number of postoperative complications and mortality rate. H. Kehlet, a professor of surgery, noted that hospitalisation is most often extended due to: incorrect analgesic treatment and associated prolonged immobilization of patients, excessive intravenous fluid supply that delays regaining of peristalsis and late start of oral feeding. H. Kehlet and his team published articles in which they argued that with holistic care it is possible to reduce patients' stay at surgical wards to 2 days. However, they have found that the publication itself will not lead to the intended changes. It was decided at the time to create a database under the patronage of the international scientific society, called the Enhanced Recovery After Surgery Society for Perioperative Care, abbreviated as ERAS Society (www.erassociety.org). Guidelines on the application of this protocol in colon, rectal and pancreatic surgery and urology were published under the aegis of the ERAS Society (Polish translation was published in "Postępy żywienia klinicznego" [title of the Polish journal, in English: Advances in Clinical Nutrition]). The goal of the ERAS protocol is to reduce metabolic stress caused by surgery by changing perioperative care. Stress reduction leads to improved wound healing, better outcomes of respiratory and motor rehabilitation, decreased incidence of complications and health care cost [16]. 
Undeniably favourable changes brought by the ERAS protocol implemented at surgical wards suggest that protocols should be developed and implemented at all surgical wards. Cooperation of the entire therapeutic team in developing standards of pre-/intra-/postoperative care will offer additional benefits, because the standard must implementable in order to be good.

\section{Summary and recommendations}

1. Communication plays a crucial role in the therapeutic process.

2. Activities undertaken by the nursing staff at surgical wards, before surgery, at the operating theatre and in postoperative rooms are very important in the therapeutic process.

3 . The communication process should entail providing information and receiving feedback.

4. Due to advanced age, the elderly may be at greater risk of perioperative complications, after unplanned surgeries in particular.

5. Interdisciplinary care of the elderly may improve surgical outcomes to a great extent.

6. Protocols, standards and procedures facilitate work of nursing teams and help reduce the incidence of intraand postoperative complications in elderly patients.

7. Nursing care at the operating theatre is a prelude for further postoperative care preventing postoperative complications.

8. Early rehabilitation is one of the ways to avoid postoperative complications.

9. Effective, targeted care improves treatment outcomes in the perioperative period.

10. If nurses determine patient's psychomotor abilities at early stage, a targeted success-oriented nursing process may be established.

11. It seems indispensable to provide training in dysfunction of elderly patients, geriatrics and care for disabled individuals.

12. If health care assistants are employed and engaged in therapeutic teams, care for elderly patients will be braced at surgical wards.

13. Patient monitoring, nursing care plan, transfer of relevant information between nurses specialized in various medical fields have significant impact on final outcome and entire treatment.

\section{REFERENCES}

1. www.senior.gov.pl

2. Leng SX. Serum levels of insulin-like growth factor-I (IGF-I) and dehydroepiandrosterone sulfate (DHEA-S), and their relationships with serum interleukin-6, in the geriatric syndrome of frailty. Aging Clin Exp Res 2004;16(2):153-7.

3. Grabowski K, Markocka-Mączka K, Tabołą R. Czy istnieją różnice w postępowaniu z pacjentem chirurgicznym w starszym wieku? Psychogeriatria Pol. 2013;10(3):109-114.

4. Michalik E. Przedoperacyjna ocena i postępowanie okołooperacyjne u chorych w wieku podeszłym. Post Nauk Med. 2008;11:712-21.

5. Drwiła R, Sadowski J. Opieka pooperacyjna u pacjentów w wieku podeszłym. Kardiol na co Dzień. 2010;5:102-7.

6. Pisarska M., Protokół ERAS (enhanced recovery after surgery) współczesna kompleksowa formuła opieki okołooperacyjnej dla poprawy wyników leczenia. www.mp.pl.

7. www.opiekunmedyczny.com.pl.

8. Bielecki K, Kaniewska A. Wiek jako czynnik ryzyka leczenia chirurgicznego chorych w podeszłym wieku. Post Nauk Med. 2008;11:708-11.

9. Poznańska S, Płaszewska-Żywko L. Wybrane modele pielęgniarstwa. Kraków: Wydawnictwo Uniwersytetu Jagiellońskiego; 2001.

10. Larsen R. Anestezjologia. Wrocław: Urban \& Partner; 2003.

11. www.imul.pl/ VII. Relacja i komunikacja z pacjentem specyficznym - osoba starsza.pdf

12. Kępiński A. Poznanie chorego. Warszawa: Wydawnictwo Literackie; 2002.

13. Makary-Studzińska M. Komunikacja z pacjentem. Lublin: Wydawnictwo Czelej; 2012.

14. Demeure MJ, Fain MJ. The elderly surgical patient and postoperative delirium. J Am Coll Surg. 2007;204(1):191.

15. Agostini J, Inouye S. Delirium. In: J. Halter, J. Ouslander, M. Tinetti, et al. (eds). Principles of geriatric medicine and gerontology. 5th ed. New York: McGraw-Hill; 2003.

16. Aguero-Torres $\mathrm{H}$, von Strauss E, Viitanen $\mathrm{M}$, et al. Institutionalization in the elderly: the role of chronic diseases and dementia. Cross-sectional and longitudinal data from a population based study. J Clin Epidemiol 2001;54(8):795-801

17. Historia i motywy powstania protokołu ERAS, który zmienił opiekę okołooperacyjną. www.mp.pl

\section{Corresponding author}

Marta Kotomska

Chair and Department of General and Transplantation Surgery, Transplantation Institute, Warszawa,

59 Nowogrodzka St., 02-006 Warszawa

E-mail: aldonano@o2.pl 